\title{
Patient preferences for treatment of multiple sclerosis with disease-modifying therapies: a discrete choice experiment
}

This article was published in the following Dove Press journal:

Patient Preference and Adherence

26 September 2016

Number of times this article has been viewed

\author{
José Manuel Garcia- \\ Dominguez' \\ Delicias Muñoz ${ }^{2}$ \\ Marta Comellas ${ }^{3}$ \\ Irmina Gonzalbo ${ }^{3}$ \\ Luis Lizán ${ }^{3}$ \\ Carlos Polanco Sánchez ${ }^{4}$ \\ 'Multiple Sclerosis Unit, Hospital \\ General Universitario Gregorio \\ Marañon, Madrid, ${ }^{2}$ Neurology \\ Department, Hospital Universitario \\ Alvaro Cunqueiro, Vigo, ${ }^{3}$ Outcomes' 10 \\ Jaime I University, Castellón, ${ }^{4} \mathrm{Health}$ \\ Economics \& Outcomes Research, \\ Merck, Madrid, Spain
}

Correspondence: Carlos Polanco Sánchez Health Economics \& Outcomes Research, Merck SL, María de Molina, 40, 28006 Madrid, Spain

$\mathrm{Tel}+34917453158$

Fax +34 91 7454444

Email carlos.polanco@merckgroup.com
Objectives: To assess disease-modifying therapy (DMT) preferences in a population of patients with multiple sclerosis (MS) and to estimate the association between sociodemographic and clinical factors and these preferences.

Methods: Preferences for DMTs attributes were measured using a discrete choice experiment. Analysis of preferences was assessed using mixed-logit hierarchical Bayes regression. A multilinear regression was used to evaluate the association between the preferences for each attribute and patients' demographic and clinical characteristics. A Student's $t$-test or Welch's $t$-test was used for subgroup comparisons.

Results: A total of 125 patients were included in the final analysis $(62.9 \%$ female, mean age 44.5 years, $71.5 \%$ with relapsing-remitting MS diagnosis). The most important factor for patients was the possibility of suffering from the side effects of the treatment (relative importance $[R I]=50 \%)$, followed by a delay in disease progression $(R I=19.4 \%)$, and route and frequency of administration ( $\mathrm{RI}=14.3 \%$ ). According to maximum acceptable risk, patients were willing to accept an increase of $3.8 \%$ in severity of side effects, for a delay of 1 year in disease progression. Treatment duration was the most prevalent factor affecting preferences, followed by the age of patients, type of MS, level of education, and the type of current treatment. Patients treated orally were significantly more concerned about the route and frequency of administration $(P=0.026)$ than patients on injectable therapy. Naïve patients stated significantly less importance to prevention of relapses $(P=0.021)$ and deterioration of the capacity for performing usual daily life activities $(P=0.015)$. Finally, patients with $>5$ years since diagnosis were significantly less concerned about preventing disease progression $(P=0.021)$, and more concerned about treatment side effects $(P=0.052)$ than compared with patients with $<5$ years of MS history.

Conclusion: The most important attribute for MS patients was side effects of DMTs, followed by delay in disability progression. Experience with DMTs and time since MS diagnosis changed patients' preferences. These results give information to adjust new DMT treatment in order to satisfy patients' preferences and therefore, improve adherence to treatment.

Keywords: multiple sclerosis, preferences, conjoint analysis, discrete choice experiment

\section{Introduction}

Multiple sclerosis (MS) is a chronic demyelinating disease of the central nervous system characterized by inflammation and axonal degeneration. It is the most common neurologic disability in young adults. ${ }^{1}$ Nearly $90 \%$ of MS patients initially experience a relapsing-remitting MS (RRMS), characterized by neurological dysfunction episodes followed by disease remission and stability. ${ }^{2}$ Over time, nearly $50 \%$ of RRMS patients gradually develop secondary progressive MS (SPMS), characterized by permanent 
disability. ${ }^{2}$ In $10 \%-20 \%$ of patients, MS gradually gets worse from the onset of symptoms, without early relapses or remissions, representing a primary progressive MS (PPMS). ${ }^{2}$

Disease-modifying therapies (DMTs) are considered a key component of comprehensive MS care. ${ }^{3}$ However, even though there is wide evidence of the benefits of DMTs in the reduction of frequency and severity of MS relapses and in slowing disease progression, ${ }^{3-5}$ treatment discontinuation in MS patients is common. ${ }^{6}$ Medication adherence and persistence have been associated with better clinical outcomes and lower MS-related medical costs. ${ }^{7}$ Treatment adherence should be considered a crucial factor in the management of these patients. It has been suggested that patient-reported outcomes may be improved by matching the treatment with the preferences and expectations of the patients.

The therapeutic options for MS have significantly increased during recent years, ${ }^{4}$ and each treatment has its unique risks and benefits..$^{5}$ For this reason, deciding on the most suitable therapeutic strategy is becoming a more complex process for both patients and physicians. Some studies report a substantial disparity between physicians' and patients' perspectives. ${ }^{8}$ This underlies the need to elucidate patients' preferences regarding their treatment, and involve them in the decision-making process. Moreover, when more than one reasonable treatment option is available, patients' preferences become more important in decision making. ${ }^{9}$

Over the past two decades, the number of publications on health-related discrete choice experiments (DCE) providing insight into patients' preferences has increased dramatically. ${ }^{10}$ These reports highlight the importance of eliciting and incorporating patient preferences in treatment decision making.

The aim of this study was to perform DCE to assess MS patients' preferences for attributes associated with DMTs and to estimate the association between sociodemographic and clinical factors and these preferences.

\section{Methods DCE}

Stated-preference methods in the form of DCE are widely used in outcomes research. They allow the identification and evaluation of patient preferences for treatment and their relative importance in decision making. ${ }^{11}$ In DCE, patients choose between two hypothetical treatment alternatives described by attributes and their corresponding levels. Attributes may include effectiveness, safety, and route and frequency of drug administration. Attribute levels describe the possible values associated with each attribute. ${ }^{11}$

The DCE was applied according to the International Society for Pharmacoeconomics and Outcomes Research
(ISPOR) good practices recommendations for conjoint analysis in health. ${ }^{12}$

\section{Attributes and levels selection}

The full set of possible attributes and levels that characterized the profiles to be evaluated in the DCE were initially identified through a literature review. Key terms were used (Table S1) to search international free-access databases recommended by the Cochrane Handbook for systematic reviews of interventions ${ }^{13}$ (MEDLINE/PubMed, Cochrane Library, ISI Web of Knowledge). The studies that assessed the preferences of MS patients for DMT attributes, published until December 31, 2014, were reviewed. A total of six previous studies related to MS patient preferences were identified. ${ }^{14-19}$

After literature review and the identification of potential attributes to include in the DCE, individual semistructured interviews by telephone with two MS specialists with vast experience in the management of MS and three MS patients were conducted. The main purpose of the semistructured interviews was to validate the potential attributes identified in the literature, to assess their relevance for MS Spanish population, to identify attributes not retrieved in the literature but relevant for MS Spanish population, and finally to assess the comprehensibility of the attributes and levels proposed. The result of literature review and semistructured interviews produced six attributes with a maximum of three levels each (Table 1).

\section{Experimental design and survey instrument}

The support.CEs package for R statistical software (Hideo Aizaki, Tsukuba, Japan) environment ${ }^{20}$ was used to generate the DCE design. Following the recommendation of ISPOR good practices for conjoint analysis in health, ${ }^{12}$ the design was orthogonal (all attributes levels vary independently and are not correlated) and balanced (each level of an attribute occurs the same number of times). Two attributes (frequency and route of administration) were redefined into one ("mode and frequency of administration") in order to avoid illogical combinations, including only realistic levels. The fractional factorial analysis (main effects orthogonal matrix) generated 36 scenarios, with a mix-and-match algorithm being used to generate the choice sets. Stated preferences were used to identify and minimize the number of dominated scenarios. Table 2 presents an example of the choice set.

To avoid participant fatigue, the inclusion of between 8 and 16 choice sets is recommended. ${ }^{12}$ For this reason, the 36 scenarios were distributed among three versions of questionnaires of 12 multiple-choice sets each. 
Table I Final attributes and levels used in the discrete choice experiment

\begin{tabular}{|c|c|}
\hline Attributes & Levels \\
\hline \multicolumn{2}{|l|}{ Route and frequency of administration } \\
\hline \multirow[t]{3}{*}{ The treatment is administered... } & Orally every day \\
\hline & Intramuscularly weekly \\
\hline & Subcutaneously several times per week \\
\hline \multicolumn{2}{|l|}{ Prevents relapses } \\
\hline \multirow[t]{2}{*}{ A relapse that needs the administration of corticosteroids may occur... } & During the first 5 years after starting treatment \\
\hline & After $>5$ years after starting treatment \\
\hline \multicolumn{2}{|l|}{ Delays progression } \\
\hline The treatment prevents the progression of disability associated with & Short term (there is no progression of disability in 2 years) \\
\hline \multirow[t]{2}{*}{ the disease in the... } & Medium term (there is no progression of disability in 5 years) \\
\hline & Long term (there is no progression of disability in 10 years) \\
\hline \multicolumn{2}{|l|}{ Side effects } \\
\hline \multirow[t]{3}{*}{ side effects may occur. } & Mild (treatment discontinuation is not required) \\
\hline & Moderate (treatment discontinuation is required temporarily) \\
\hline & Severe (serious or life-threatening) \\
\hline \multicolumn{2}{|l|}{ Impact on daily life } \\
\hline \multirow[t]{2}{*}{ Discomfort may occur that... } & Does not affect your daily life or everyday activities \\
\hline & Affects your daily life or everyday activities \\
\hline \multicolumn{2}{|l|}{ Treatment follow-up } \\
\hline Treatment follow-up needing you to visit & Once a month \\
\hline \multirow[t]{2}{*}{ the doctor... } & Every 3 months \\
\hline & Every 6 months \\
\hline
\end{tabular}

In addition to the choice sets, the survey instrument collected patients' sociodemographic and clinical variables. Each participant received a randomly assigned version of the questionnaire.

Before answering the questionnaire, all participants received a clear explanation stating that all presented treatments scenarios were hypothetical.

\section{Study participants}

Patients with MS were contacted through Spanish MS patient associations and invited by e-mail. The participants received a personal access password and the link to the electronic questionnaire that was hosted in a website. The questionnaire was available between September 2015 and November 2015.

All patients provided written informed consent to participate in the study. Their data were treated confidentially and dissociated in accordance with Spanish regulations (15/1999 Personal Data Protection Law). Patients were blinded to the sponsor of the study and no incentives were offered to any of the participants for questionnaire completion.

Patients aged 18 years or older with a diagnosis of RRMS or SPMS (MS type was reported by the patient and not confirmed by any other data source) were included in the study.

Table 2 Example of the choice set

\begin{tabular}{|c|c|c|c|c|}
\hline & \multicolumn{2}{|c|}{ Treatment A } & \multicolumn{2}{|c|}{ Treatment B } \\
\hline The treatment is administered... & \multicolumn{2}{|c|}{ Intramuscular weekly } & \multicolumn{2}{|l|}{ Oral daily } \\
\hline $\begin{array}{l}\text { A relapse that needs the administration } \\
\text { of corticosteroids may occur... }\end{array}$ & \multicolumn{2}{|c|}{$\begin{array}{l}\text { During the first } 5 \text { years after starting } \\
\text { treatment }\end{array}$} & \multicolumn{2}{|c|}{$\begin{array}{l}\text { During the first } 5 \text { years after starting } \\
\text { treatment }\end{array}$} \\
\hline $\begin{array}{l}\text { The treatment prevents the progression } \\
\text { of disease-related disability in the... }\end{array}$ & \multicolumn{2}{|c|}{$\begin{array}{l}\text { Long term (there is no progression } \\
\text { of disability in } 10 \text { years) }\end{array}$} & \multicolumn{2}{|c|}{$\begin{array}{l}\text { Medium term (there is no } \\
\text { progression of disability in } 5 \text { years) }\end{array}$} \\
\hline side effects may occur. & \multicolumn{2}{|c|}{$\begin{array}{l}\text { Mild (treatment discontinuation } \\
\text { is not required) }\end{array}$} & \multicolumn{2}{|c|}{$\begin{array}{l}\text { Mild (treatment discontinuation is } \\
\text { not required) }\end{array}$} \\
\hline & & 100 & 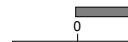 & 100 \\
\hline & $\begin{array}{c}\text { Better } \\
\text { health status }\end{array}$ & $\begin{array}{c}\text { Worst } \\
\text { health status }\end{array}$ & $\begin{array}{c}\text { Better } \\
\text { health status }\end{array}$ & $\begin{array}{c}\text { Worst } \\
\text { health status }\end{array}$ \\
\hline Discomfort may occur that... & \multicolumn{2}{|c|}{$\begin{array}{l}\text { Affects your daily life or everyday } \\
\text { activities }\end{array}$} & \multicolumn{2}{|c|}{$\begin{array}{l}\text { Affects your daily life or everyday } \\
\text { activities }\end{array}$} \\
\hline \multirow{2}{*}{$\begin{array}{l}\text { Treatment follow-up needing you to visit the } \\
\text { doctor... }\end{array}$} & \multicolumn{2}{|c|}{ I visit per month } & \multicolumn{2}{|c|}{ Every 6 months } \\
\hline & \multicolumn{2}{|c|}{$\square$ I prefer A } & \multicolumn{2}{|c|}{$\square$ I prefer B } \\
\hline
\end{tabular}




\section{Study sample and data collection procedures}

The minimum sample size necessary for the DCE was established according to a rule-of-thumb and recommendation proposed by Orme ${ }^{21} \frac{n t a}{c} \geq 500$, where $n$ is the number of respondents, $t$ is the number of tasks ( $t=36$ scenarios), $a$ is the number of alternatives per task ( $a=2$ alternatives), and $c$ is the largest number of levels for any one attribute ( $c=3$ maximum number of levels). As a result, a minimum number of $125 \mathrm{MS}$ patients had to complete the survey.

\section{Statistical analyses}

Analysis of preferences was assessed using a mixed-logit model (random parameters logit) (RSGHB R package ${ }^{22}$ ). This model enhances the multinomial logit by allowing the coefficients to randomly vary across respondents, thus leading to individual sets of utility values rather than mean preferences, which foster more accurate further analysis.

Statistical analyses of patient characteristics were performed using SPSS 20.0 (IBM Corporation, Armonk, NY, USA). Possible explanatory variables for the preferences were analyzed by consecutively evaluating the individual partial utility values and the relative importance of the attributes (as dependent variables) against the potential explanatory variables (individuals' demographic or clinical facts). After analyzing possible correlations between them (Pearson's correlation coefficients), multilinear regressions (stepwise method) were applied to the dependent variables using the demographic and clinical factors as independent. The Student's $t$-test or Welch's $t$-test (whether for equal or unequal variances) were run to assess subgroup comparisons as suggested by the stepwise results. In case of more than two subgroups, analysis of variance with a least significant difference post hoc test was performed.

Maximum acceptable risk (MAR) was estimated as the quotient between two utility differences, one associated with an improvement in outcomes and the other with a less desirable attribute. ${ }^{23}$

\section{Ethical consideration}

The study followed the principles of the Declaration of Helsinki. It was developed to ensure compliance with good clinical practices, in keeping with the principles of the Tripartite Harmonized International Conference on Harmonization Guideline ${ }^{24}$ (International Conference on Harmonization, 1996). The study protocol was submitted to the Spanish Agency of Medicines and Medical Devices (Agencia Española del Medicamento y Productos Sanitarios) for classification and to the Clinical Research Ethics Committee of Bellvitge University Hospital (Barcelona) for approval, which was granted.

\section{Results \\ Patient demographics}

One hundred and forty-six patients completed the electronic questionnaire. Of these, 125 patients were included in the final data analysis. Twenty-one patients (14\%) with a PPMS diagnosis were excluded from the analysis after the study selection criteria were applied. Given that patients were contacted through patient associations, no previous verification of their MS diagnosis could be done until data analysis.

The mean age of participants was 44.5 years (standard deviation [SD]: 10.9), most of whom were females (62.9\%) and married or living with a partner (63.2\%). Half of the participants had completed higher education (university or postgraduate) and $36.8 \%$ were employed. Mean time since MS diagnosis was 13.4 years (SD: 7.9). Most of the participants had a RRMS diagnosis (71.5\%). Among current treatment, the most common current route of administration was oral (43.4\%), followed by subcutaneous (26.3\%). Mean time on MS treatment (time since MS treatment initiation) was 9.3 years (SD: 6.2), and the mean time on current treatment was 4.3 years (SD: 5.2). Ten patients (8\%) had never received MS treatment. Mean time between patients' MS diagnosis and the initiation of MS treatment was 4.8 years (SD: 7.3) (Table 3).

\section{MS patients' preferences for DMT attribute levels}

Table 4 and Figure 1 show the results of the mixed logit of patient preferences for DMTs. To obtain the partial utilities (preference scores expressed as odds ratios [ORs]) for levels within the attributes, beta coefficients from the mixed logit were exponentiated. All levels addressing route and frequency of administration, disease progression, side effects, and daily life activities were statistically significant as determinants of patients' preferences. Relapse prevention and treatment follow-up were not significantly associated with preferences.

The results of the analysis showed that subcutaneous treatment administered several times a week (OR: $0.428 ; P<0.01$ ) and intramuscular injections given weekly (OR: $0.389 ; P<0.01)$ was less preferred, compared with daily oral administration. As expected, higher treatment efficacy (reduction of disability progression over 10 years vs reduction of disability over 2 years) (OR: 3.597; $P<0.01)$ was preferred. Treatments associated with severe side effects (serious or life-threatening) (OR: 0.034; $P<0.01)$ or that significantly compromised patients' daily life (OR: $0.468 ; P<0.01$ ) were less preferred.

\section{Relative importance of each attribute}

The relative importance of each attribute was calculated to establish their importance in treatment decision making. 
Table 3 Participant sociodemographic and clinical characteristics $(n=125)$

\begin{tabular}{ll}
\hline Characteristic & \% of patients \\
or mean (SD)
\end{tabular}

Abbreviations: IM, intramuscular; IV, intravenous; MS, multiple sclerosis; RRMS, relapsing-remitting MS; SPMS, secondary-progressive MS; SC, subcutaneous; SD, standard deviation.

Among all of the attributes studied, the probability of suffering treatment side effects was the most important attribute to patients, and influenced half of their decision-making processes. Delayed progression and route and frequency of administration were also important for patients' decisions, representing $19.4 \%$ and $14.3 \%$ of importance, respectively (Figure 2).

\section{Maximum acceptable risk}

By estimating the MAR, the maximum risk that patients are willing to accept in order to achieve a therapeutic benefit of pharmacotherapy can be assessed. ${ }^{25}$ Patients were willing to accept a severity increase of $3.8 \%$ in side effects for a delay of 1 year in disease progression.

\section{Factors defining preferences}

Explanatory variables for the revealed preferences were analyzed using stepwise multilinear regression. When partial utilities (preference scores) were used as dependent variables, and sociodemographic and clinical characteristics as independent variables, the results (Table 5) showed that actual duration of treatment was the most prevalent factor affecting preferences, followed by patient age, type of MS, level of education and the type of treatment currently received. Figure 3 shows the variation in patients' preferences regarding the side effects according to patients' age and level of education. Older patients were more concerned about side effects. On the other hand, people with higher education were less concerned about side effects development. Figure 4 shows that patients who had been receiving their current treatment for longer duration were more willing to accept subcutaneous treatment several times per week or intramuscular weekly. This preference was stronger when patients had a RRMS diagnosis, compared with a SPMS diagnosis.

When the relative importance of the attributes were used as dependent variables, the regression showed that actual treatment duration was again the most influential factor, followed by educational level and age (Table 6).

Regression analysis results suggested that it would be interesting to make comparisons between subgroups, so we proceeded to conduct these analyses.

\section{Current route of administration}

A total of 99 patients of the study population were receiving treatment during the study and included for analysis. The analysis ( $t$-tests for independent samples) of the subgroup of patients that were receiving treatment $(n=99$, Table 2$)$ showed that patients treated orally $(n=43)$ were significantly more concerned about the route and frequency of administration $(15.9 \%$ vs $12.1 \%, P=0.026)$ than other patients $(\mathrm{n}=47)$ and, in a less significant but also relevant measure, they differed in the importance assigned to the impact on daily life (7.7\% vs $9.9 \%, P=0.09$ ) (Figure 5).

\section{Previous experience with treatment}

Patients were divided into five groups depending on their experience on treatment (naïve $[n=10], 0-5$ years $[n=29]$, $5-10$ years $[\mathrm{n}=30], 10-15$ years $[\mathrm{n}=28]$, and $>15$ years $[\mathrm{n}=24]$ ) and the analysis of variance test was performed. Although no significant differences were revealed at a $P \leq 0.05$ level, preferences changed in naïve patients with respect to the other patients (Figure 6). A Welch's $t$-test was conducted to evaluate differences between naïve and experienced patients. Naïve patients gave significantly 
Table 4 MS patient preferences

\begin{tabular}{|c|c|c|c|c|c|}
\hline Attribute & Level & Coefficients & OR & SE & $P$-value \\
\hline Route and & Oral daily (reference) & 0 & I & - & - \\
\hline frequency of & Intramuscular weekly & -0.849 & 0.428 & 0.113 & $<0.0$ I \\
\hline administration & Subcutaneous several times per week & -0.943 & 0.389 & 0.103 & $<\mathbf{0 . 0 1}$ \\
\hline Prevents & $<5$ years (reference) & 0 & I & - & - \\
\hline relapses & $>5$ years & 0.066 & 1.068 & 0.101 & 0.513 \\
\hline Delays & Per year & 0.128 & 1.137 & 0.013 & $<0.01$ \\
\hline \multirow[t]{2}{*}{ progression } & $\begin{array}{l}2 \text { years } \\
5 \text { years }\end{array}$ & $\begin{array}{l}0.256 \\
0.640\end{array}$ & $\begin{array}{l}1.292 \\
1.896\end{array}$ & $\begin{array}{l}- \\
-\end{array}$ & $\begin{array}{l}- \\
-\end{array}$ \\
\hline & 10 years & 1.280 & 3.597 & - & - \\
\hline \multirow[t]{4}{*}{ Side effects } & Per $100 \%$ of severity & -3.388 & 0.034 & 0.204 & $<\mathbf{0 . 0}$ I \\
\hline & Mild & -1.118 & 0.327 & - & - \\
\hline & Moderate & -2.236 & 0.107 & - & - \\
\hline & Severe & -3.388 & 0.034 & - & - \\
\hline Impact on & No impact (reference) & 0 & I & - & - \\
\hline daily life & Impact & -0.760 & 0.468 & 0.099 & $<0.0$ I \\
\hline Treatment & Per monthly visit & -0.149 & 0.862 & 0.134 & 0.267 \\
\hline \multirow[t]{2}{*}{ follow-up } & $\begin{array}{l}\text { I visit every } 6 \text { months } \\
\text { I visit every } 3 \text { months }\end{array}$ & $\begin{array}{l}-0.025 \\
-0.050\end{array}$ & $\begin{array}{l}0.975 \\
0.952\end{array}$ & $\begin{array}{l}0.89 \\
0.8\end{array}$ & $\begin{array}{l}0.92 \\
0.85\end{array}$ \\
\hline & I visit per month & -0.149 & 0.862 & 0.54 & 0.68 \\
\hline
\end{tabular}

Note: Bold text indicates statistically significant value.

Abbreviations: MS, multiple sclerosis; OR, odds ratio; SE, standard error.

less importance to prevention of relapses $(2.1 \%$ vs $3.1 \%$; $P=0.021$ ), deterioration of ability to perform usual daily life activities $(6.1 \%$ vs $9.2 \% ; P=0.015)$, and prevention of progression (14.8\% vs $20.0 \%$ ). They were more concerned about the route and frequency of administration $(18.0 \%$ vs $13.4 \%)$, side effects $(52.0 \%$ vs $48.6 \%)$, and treatment follow-up $(7.0 \%$ vs $5.8 \%)$.

\section{Time since MS diagnosis}

Patients with $<5$ years of MS history $(n=15)$ were significantly less concerned about preventing progression than patients with 5 or more years since diagnosis $(n=109)(13.5 \%$ vs $20.3 \% ; P=0.021$ ), and more concerned about treatment side effects $(54.8 \%$ vs $48.3 \% ; P=0.052)$.

\section{Discussion}

This study explored Spanish MS patients' preferences for DMT characteristics. The study population had a mean age, sex and MS type comparable with national MS statistics. ${ }^{26}$

In line with previous studies, the results of this DCE revealed that treatment side effects were the most important attribute defining DMT preferences. Recently, Wicks et al ${ }^{27}$ reported that in oral DMT-naïve patients, liver toxicity, severe side effects, and common side effects were the attributes that emerged as the most important drivers of patients' preferences; and patients expressed greater preference for product profiles with fewer serious side effects and fewer common side effects compared with those with higher efficacy. Similarly, Wilson et a ${ }^{19}$ found that severe side effect

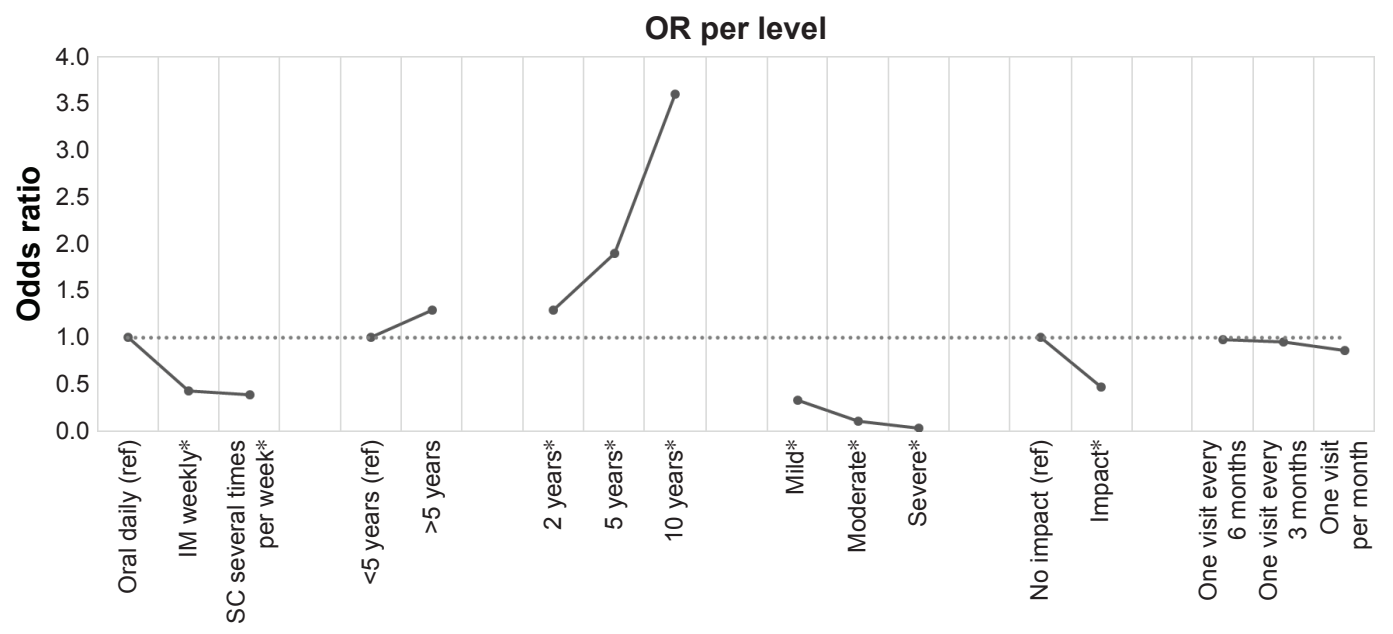

Figure I Preferences for levels within each attribute.

Note: $* P<0.01$.

Abbreviations: IM, intramuscular; OR, odds ratio; ref, reference; SC, subcutaneous. 
Table 5 Stepwise multilinear regression of partial utilities

\begin{tabular}{|c|c|c|}
\hline Attribute & Coefficient & $P$-value \\
\hline \multicolumn{3}{|c|}{ Route and frequency of administration: } \\
\hline \multicolumn{3}{|c|}{ subcutaneously several times per week } \\
\hline (Intercept) & -1.055 & $<0.00 I^{*}$ \\
\hline Age & -0.011 & 0.107 \\
\hline SPMS (I) & -0.298 & 0.084 \\
\hline Actual treatment duration & 0.046 & $0.004^{*}$ \\
\hline Actual treatment: oral (2) & -0.241 & 0.051 \\
\hline \multirow{2}{*}{\multicolumn{3}{|c|}{$\begin{array}{l}\text { Route and frequency of administration: } \\
\text { intramuscular weekly }\end{array}$}} \\
\hline & & \\
\hline (Intercept) & -1.412 & $<0.00 I^{*}$ \\
\hline SPMS & -0.418 & $0.032 *$ \\
\hline Actual treatment duration & 0.049 & $0.003^{*}$ \\
\hline \multicolumn{3}{|l|}{ Prevents progression } \\
\hline (Intercept) & 0.051 & 0.597 \\
\hline Age & 0.005 & 0.050 \\
\hline Higher education (3) & 0.059 & 0.160 \\
\hline Time with MS & -0.006 & 0.112 \\
\hline \multicolumn{3}{|l|}{ Prevents relapses } \\
\hline (Intercept) & 0.381 & $<0.00 I^{*}$ \\
\hline Woman (4) & -0.069 & 0.144 \\
\hline \multicolumn{3}{|l|}{ Side effects } \\
\hline (Intercept) & -4.932 & $<0.00 I^{*}$ \\
\hline Age & -0.061 & $0.022 *$ \\
\hline Higher education & 1.042 & $0.025^{*}$ \\
\hline Total treatment duration & 0.080 & 0.064 \\
\hline \multicolumn{3}{|l|}{ Impact on daily life } \\
\hline (Intercept) & -1.291 & $<0.00 I^{*}$ \\
\hline Age & 0.010 & 0.062 \\
\hline Actual treatment duration & -0.026 & $0.03 I^{*}$ \\
\hline \multicolumn{3}{|l|}{ Treatment follow-up } \\
\hline Age & -0.017 & $<0.001$ \\
\hline Actual treatment duration & 0.029 & 0.023 \\
\hline
\end{tabular}

risks had a higher impact on RRMS patient preferences. Furthermore, patients were willing to accept a relatively greater risk of death/disability as long as the benefit gained was substantial.

With regard to treatment efficacy, our findings showed that a delay in years to disability progression was the second most important DMT attribute in treatment choice. In contrast, relapse prevention was the least important DMT attribute. Several studies reported similar results, showing that MS patients strongly preferred preventing long-term disability progression over preventing relapses. ${ }^{14,19,27,28}$ According to the MAR assessed in this study, MS patients were willing to accept a change in the severity of side effects from mild to moderate or moderate to severe (33\% increment in severity) in order to delay disease progression by 10 years.

This study also aimed to elicit patient preferences regarding DMT route and frequency of administration, showing that, as observed in previous studies, ${ }^{19}$ patients strongly preferred oral daily medications compared with other routes and frequencies.

Subgroup analysis showed that experience with MS and MS treatment changes patients' perceptions and values. Patients receiving oral treatment gave more importance to the route and frequency of administration than patients currently on injectable therapies. A review published by Bansback et $\mathrm{al}^{29}$ showed that experienced patients on treatments for rheumatic diseases who perceived their routes of administration as fairly convenient assigned lower values to more suitable treatments.

Despite the small group of naïve patients $(n=10)$ in this study, the results suggested that these patients gave less

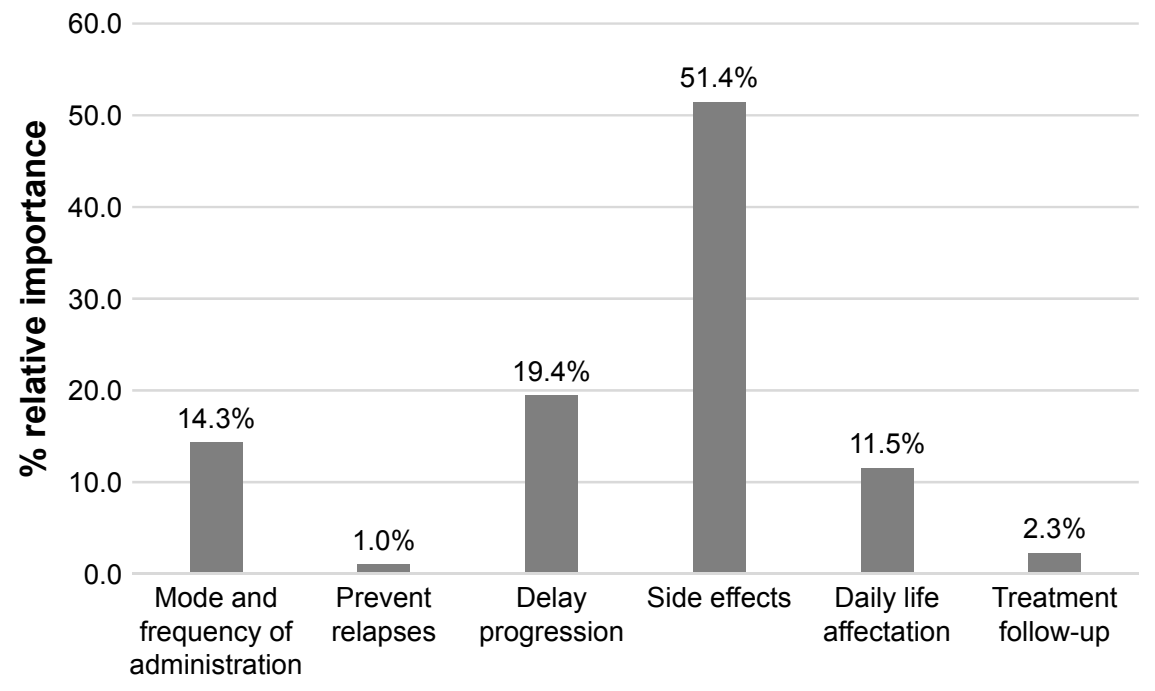

Figure 2 Relative importance in patients' decisons. 


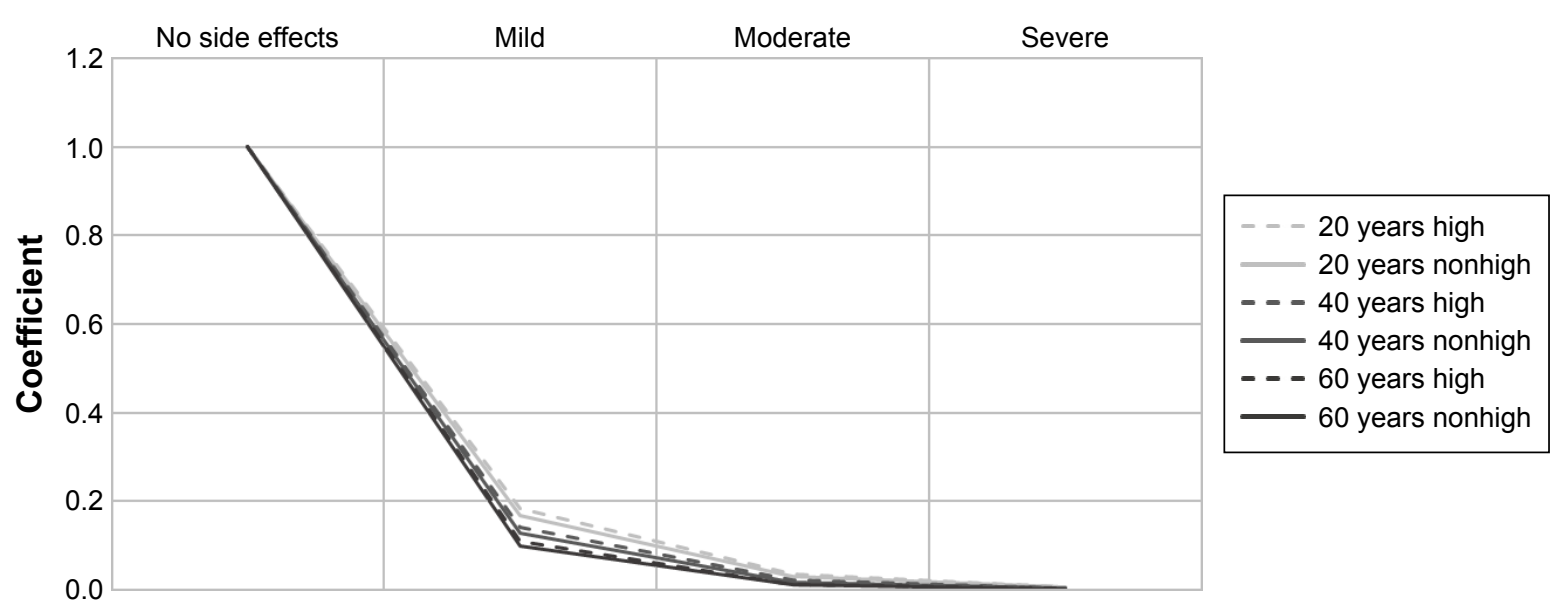

Figure 3 Preference for side effects by patients' age and level of education.

Notes: 20 years high: patient aged 20 years with high level of education; 20 years nonhigh: patient aged 20 years without high level of education; 40 years high: patient aged 40 years with high level of education; 40 years nonhigh: patient aged 40 years without high level of education; 60 years high: patient aged 60 years with high level of education; 60 years nonhigh: patient aged 60 years without high level of education. Patients' age: $P=0.0224$; level of education: $P=0.0254$.

importance to the attributes related to treatment efficacy, and were more concerned about the route and frequency of administration and treatment-related side effects. A study performed in the Netherlands to gain insight into the reasons why MS patients use or do not use DMTs showed that for naïve patients, awareness about possible side effects was the most important reason for not adopting DMTs. In contrast with our findings, these authors observed that neither the route nor frequency of treatment administration were related to the patients' decision to not start a DMT. ${ }^{30}$ Instead, time since diagnosis also affected patients' treatment preferences. Thus, results from our study showed that compared with patients with $>5$ years since diagnosis, patients who were more recently diagnosed ( $<5$ years) worried more about side effects of treatment and were less concerned about treatment efficacy in the delay of MS progression.
The study results highlight the importance of eliciting and incorporating patient preferences in treatment decision making and evidence that, in order to improve treatment adherence and satisfaction, physicians should discuss with patients on their preferences of therapy options.

\section{Study limitations}

Our study had limitations. Although DCE is the recommended approach and it is widely used to assess patient preferences for treatment characteristics, there is always the risk of a gap between stated and revealed preferences. ${ }^{12,31}$ Half of the study participants had completed higher education, but uncertainty in interpreting the scenarios may have existed which could have affected the results. Despite the selection of the choice levels being performed according to the ISPOR recommendations, and after semistructured

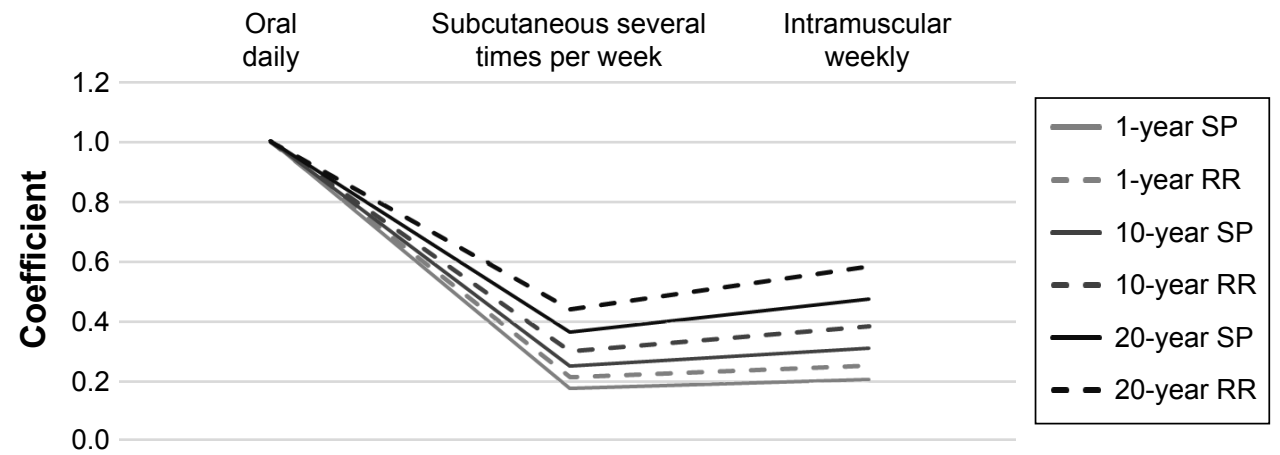

Figure 4 Preference for the route and frequency of administration by duration of the current treatment and type of multiple sclerosis.

Notes: I-year SP: patient with I year in current treatment and diagnosis of SPMS; I-year RR: patient with I year in current treatment and diagnosis of RRMS; I0-year SP: patient with 10 years in current treatment and diagnosis of SPMS; 10-year RR: patient with 10 years in current treatment and diagnosis of RRMS; 20 -year SP: patient with 20 years in current treatment and diagnosis of SPMS; 20 -year RR: patient with 20 years in current treatment and diagnosis of RRMS. Duration of the current treatment: $P=0.004$ for subcutaneous several times per week and $P=0.0034$ I for intramuscular weekly; type of MS (SP): $P=0.03233$.

Abbreviations: MS, multiple sclerosis; RR, relapse-remitting; RRMS, relapsing-remitting MS; SPMS, secondary-progressive MS; SP, secondary progressive. 
Table 6 Stepwise multilinear regression of relative importance

\begin{tabular}{lll}
\hline Attribute & Coefficient & P-value \\
\hline $\begin{array}{l}\text { Route and frequency } \\
\text { of administration } \\
\text { (Intercept) }\end{array}$ & & \\
Total treatment duration & $13.42 \%$ & $<0.00$ I \\
Actual treatment duration & $0.28 \%$ & 0.069 \\
Prevents relapses & $-0.49 \%$ & 0.022 \\
(Intercept) & & \\
Age & $3.30 \%$ & $<0.00$ I \\
Higher education (I) & $-0.03 \%$ & 0.075 \\
Time with MS & $0.80 \%$ & 0.01 I \\
Prevents progression & $0.06 \%$ & 0.025 \\
(Intercept) & & \\
Higher education & $16.22 \%$ & $<0.00$ I \\
Side effects & $5.05 \%$ & 0.034 \\
(Intercept) & & \\
Higher education & $53.40 \%$ & $<0.00$ I \\
Impact on daily life & $-7.73 \%$ & 0.003 \\
(Intercept) & & \\
Age & $14.02 \%$ & $<0.00$ I \\
Actual treatment duration & $-0.17 \%$ & 0.028 \\
Treatment follow-up & $0.50 \%$ & 0.004 \\
(Intercept) & & 0.0129 \\
Age & $3.18 \%$ & 0.0255 \\
Actual treatment duration & $0.07 \%$ & \\
\hline Note: (I) Ref Ievel: & $-0.11 \%$ & \\
\hline
\end{tabular}

Note: (I) Ref. level: nonuniversity level education. Abbreviations: MS, multiple sclerosis; Ref., reference.

interviews with MS experts and MS patients, some relevant attributes for patients may have been omitted from this study and some of the attributes might not match the currently available treatments. For this reason, all participants received a clear explanation before answering the questionnaire stating that all presented treatments were hypothetical and in no case were to be compared against their current treatment.
Moreover, in order to reduce the complexity of the DCE, and as performed in previous studies, ${ }^{28,32}$ in this analysis a decision was made to limit the number of attributes. For this reason, route and frequency of administration were presented combined in the same attribute. This could be a possible limitation of the study, since Utz et a $1^{18}$ published that the preference for oral DMTs changes when the frequency of the oral treatment is substantially higher than the frequency of injectable treatment. Even though the classification of side effects used in the study is not necessarily suited to categorize side effects in daily practice, semistructured interviews with patients and MS physicians revealed that, since severity of side effects is perceived differently for each patient, it will be more easy for them to evaluate each level of this attribute using the description of mild, moderate, and severe instead of describing side effects such as headache or flu-like symptoms. Due to the small sample size of some study subgroups, any extrapolation of results should be done with caution. Further research regarding preferences of patients in these subgroups is warranted. The comparison between patients' subjective thoughts and physicians' data may increase the strength of our results, however, since patients were contacted through patient's associations, physicians' data were not available, and this comparison was not possible to be performed. Finally, these results should be interpreted within the context of the study.

\section{Conclusion}

Our findings indicate that the most important attributes for MS patients were treatment side effects and the delay in progression of disability.

Experience with DMTs changed patients' preferences. Patients receiving oral treatment gave more importance to the

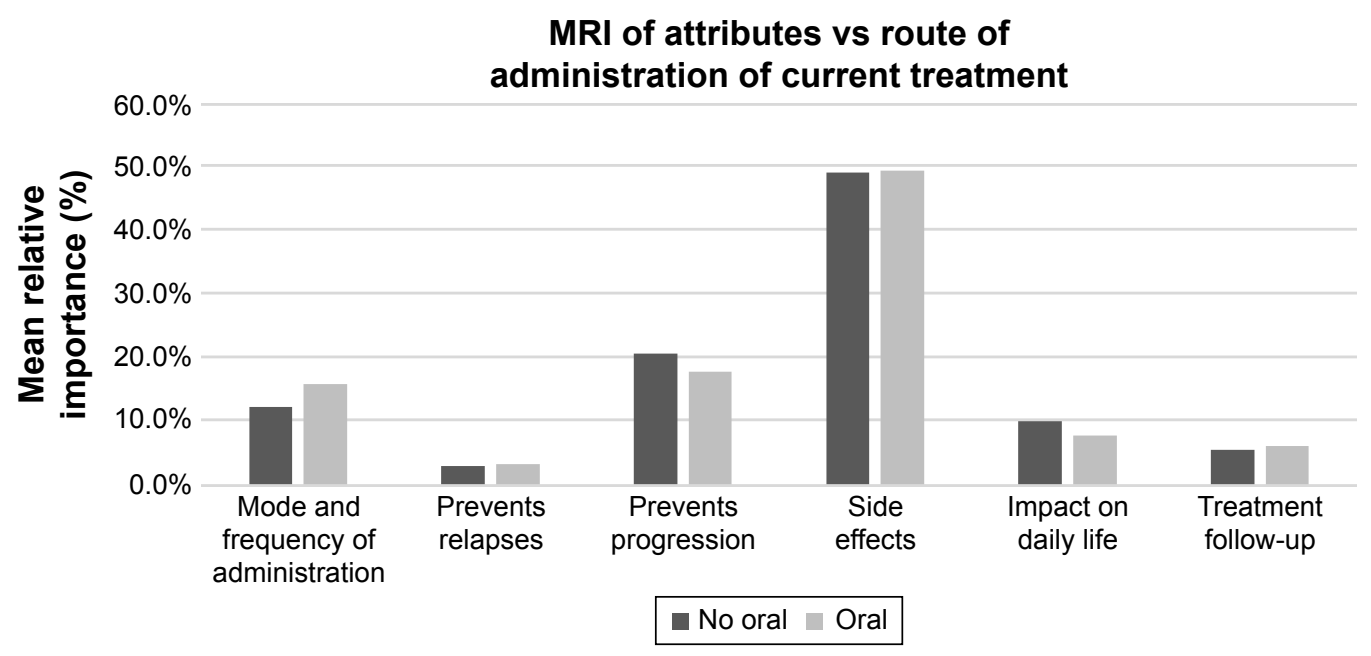

Figure $5 \mathrm{MRI}$ of attributes by route of administration.

Abbreviation: MRI, mean relative importance. 


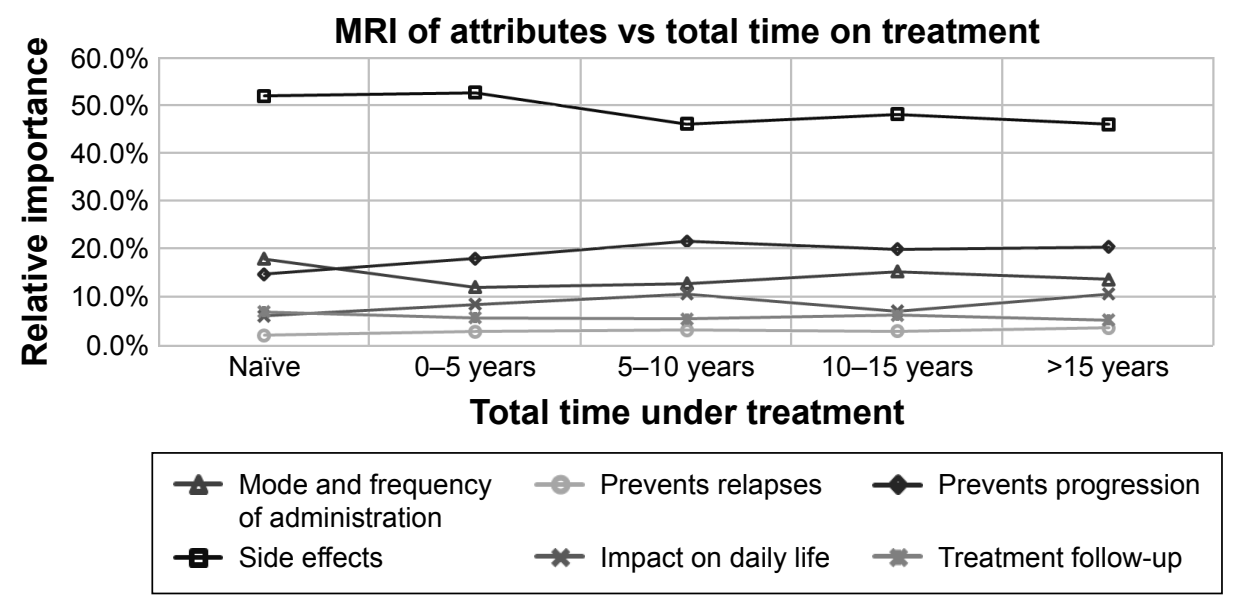

Figure $6 \mathrm{MRI}$ of attributes by total time on treatment. Abbreviation: MRI, mean relative importance.

route and frequency of administration than patients treated with injectable therapies. Naïve patients were also concerned about this attribute in addition to treatment side effects, giving less importance to attributes related to treatment efficacy.

Time since MS diagnosis also affected patients' preferences, with more recently diagnosed patients being more concerned about side effects than patients diagnosed $>5$ years ago. These results are important since they give information to adjust new DMT treatment in order to satisfy patients' preferences and therefore, improve adherence to treatment.

\section{Acknowledgments}

This study was funded by Merck Serono. We are very grateful to all the patient associations and the study participants who devoted their time to participating in this research.

\section{Author contributions}

All authors oversaw the development of the study, and the analysis and interpretation of results. They significantly contributed to the conception, design, progress, and conclusion of the study. All authors critically reviewed preliminary drafts for important intellectual content and contributed to its final version. They all gave final approval of the version being submitted.

\section{Disclosure}

The study was sponsored by Merck Serono, Spain, a subsidiary of Merck KGaA, Darmstadt, Germany. The authors report no other conflicts of interest in this work.

\section{References}

1. Murray TJ. Diagnosis and treatment of multiple sclerosis. BMJ. 2006; 332(7540):525-527.
2. Tremlett H, Zhao Y, Rieckmann P, Hutchinson M. New perspectives in the natural history of multiple sclerosis. Neurology. 2010; 74(24):2004-2015.

3. Cross AH, Naismith RT. Established and novel disease-modifying treatments in multiple sclerosis. J Intern Med. 2014;275(4):350-363.

4. Gajafatto A, Benedetti MD. Treatment strategies for multiple sclerosis: when to start, when to change, when to stop? World J Clin Cases. 2015; 3(7):545-555.

5. Lugaresi A, di Ioia M, Travaglini D, Pietrolongo E, Pucci E, Onofrj M. Risk-benefit consideration in the treatment of relapsing-remitting multiple sclerosis. Neuropsychiatr Dis Treat. 2013;9:893-914.

6. Tobin W, Weinshenker BG. Stopping immunomodulatory medications in MS: frequency, reasons and consequences. Mult Scler Relat Disord. 2015;4(5):437-443.

7. Lizán L, Comellas M, Paz S, Poveda JL, Meletiche DM, Polanco C. Treatment adherence and other patient-reported outcomes as cost determinants in multiple sclerosis: a review of the literature. Patient Prefer Adherence. 2014;8:1653-1664.

8. Riñon A, Buch M, Holley D, Verdun E. The MS choices survey: findings of a study assessing physician and patient perspectives on living and managing multiple sclerosis. Patient Prefer Adherence. 2011;5:629-643.

9. Mendel R, Traul-Mattausch E, Frey D, et al. Do physicians' recommendations pull patients away from their preferred treatment options? Health Expect. 2012;15(1):23-31.

10. Clark Determann D, Petrou S, Moro D, Bekker-Grob EW. Discrete choice experiments in health economics: a review of the literature. Pharmacoeconomics. 2014;32(9):883-902.

11. Johnson RF, Lancsar E, Marshall D, et al. Constructing experimental design for discrete-choice experiments: report of the ISPOR conjoint analysis experimental design good research practices task force. Value Health. 2013;16(1):3-13.

12. Bridges JFP, Hauber AB, Marshall D, et al. Conjoint analysis applications in health: a checklist of the ISPOR good research practices for conjoint analysis task force. Value Health. 2011;14(4):403-413.

13. Higgins JPT, Green S (editors). Cochrane handbook for systematic reviews of interventions version 5.1.0 [updated March 2011]. The Cochrane Collaboration; 2011. Available from: http://handbook.cochrane.org/

14. Johnson FR, Van Houtven G, Özdemir S, et al. Multiple sclerosis patient's benefit-risk preferences: serious adverse event risks versus treatment efficacy. J Neurol. 2009;256(4):554-562.

15. Hanson KA, Agashivala N, Wyrwich KW, Raimundo K, Kim E, Brandes DW. Treatment selection and experience in multiple sclerosis: survey of neurologists. Patient Prefer Adherence. 2014;8:415-422.

16. Glass-Marmor L, Paperna T, Ben-Yosef Y, Miller A. Chronotherapy using corticosteroids for multiple sclerosis relapses. J Neurol Neurosurg Psychiatry. 2007;78(8):886-888. 
17. Shingler SL, Swinburn P, Ali S, Perard R, Lloyd AJ. A discrete choice experiment to determine patient preferences for injection devices in multiple sclerosis. J Med Econ. 2013;16(8):1036-1042.

18. Utz KS, Hoog J, Wentrup A, et al. Patient preferences for diseasemodifying drugs in multiple sclerosis therapy: a choice-based conjoint analysis. Ther Adv Neurol Disord. 2014;7(6):263-275.

19. Wilson L, Loucks A, Bui C, et al. Patient centered decision making: use of conjoint analysis to determine risk-benefit trade-offs for preference sensitive treatment choices. J Neurol Sci. 2014;344(1-2):80-87.

20. Aizaki H. Basic functions for supporting an implementation of choice experiments in R. J Stat Softw. 2012;50(2):1-24.

21. Orme B. Getting Started with Conjoint Analysis: Strategies for Product Design and Pricing Research. 2nd ed. Madison WI. Research Publishers LLC; 2010;57-66.

22. Dumont J, Keller J. RSGHB: functions for hierarchical Bayesian estimation: a flexible approach. Available from: https://cran.r-project.org/ web/packages/RSGHB/index.html. Accessed March 2016.

23. Bridges JF, Hauber AB, Marshall D, et al. Conjoint analysis applications in health - a checklist: a report of the ISPOR good research practices for conjoint analysis task force. Value Health. 2011;14(4):403-413.

24. International conference on harmonization of technical requirements for registration of pharmaceuticals for human use. ICH harmonized tripartite guideline: guideline for good clinical practice E6(R1); 1996. Available from: http:/www.ich.org/fileadmin/Public_Web_Site/ ICH_Products/Guidelines/Efficacy/E6/E6_R1_Guideline.pdf. Accessed March, 2016.

25. Hauber AB, Johnson R, Andrews EB. Risk-benefit analysis methods for pharmaceutical decision-making - where are we now? ISPOR Connection; 2006;12(6). Available from: https:/www.rtihs.org/sites/ default/files/Hauber,\%20Johnson,\%20et\%20al._2006_Risk-Benefit_ ISPOR\%20Connections.pdf. Accessed March, 2016.
26. Otero-Romero S, Ramió-Torrentà LL, Pericot I, et al. Onset-adjusted incidence of multiple sclerosis in the Girona province (Spain): evidence of increasing risk in the south of Europe. J Neurol Sci. 2015; 359(1-2):146-150.

27. Wicks P, Brandes D, Park J, Liakhovistski D, Koudinova T, Sasane R. Preferred features of oral treatments and predictors of non-adherence: two web-based choice experiments in multiple sclerosis patients. Interact J Med Res. 2015;4(1):e6.

28. Wilson LS, Loucks A, Gipson G, et al. Patient preferences for attributes of multiple sclerosis disease-modifying therapies. Int J MS Care. 2015;17(2):74-82.

29. Bansback N, Trenaman L, Harrison M. How important is mode of administration in treatments for rheumatic diseases and related conditions? Curr Rheumatol Rep. 2015;17(6):514.

30. Visser LH, van der Zande A. Reasons patients give to use or not to use immunomodulating agents for multiple sclerosis. Eur J Neurol. 2011; 18(11):1343-1349.

31. Viney R, Lanesar E, Louviere J. Discrete choice experiments to measure consumer preferences for health and healthcare. Expert Rev Pharmacoecon Outcomes Res. 2002;2(4):89-96.

32. Morillas C, Feliciano R, Catalina PF, et al. Patients' and physicians' preferences for type 2 diabetes mellitus treatments in Spain and Portugal: a discrete choice experiment. Patient Prefer Adherence. 2015;9:1443-1458. 


\section{Supplementary material}

Table SI Search terms and search strategy

\begin{tabular}{|c|c|}
\hline Search terms & \\
\hline \#I & "Multiple sclerosis" \\
\hline$\# 2$ & “MS” \\
\hline \#3 & \#I OR \#2 \\
\hline$\# 4$ & "Conjoint analysis" \\
\hline \#5 & "Choice model" \\
\hline \#6 & "Stated preference" \\
\hline \#7 & “DCE” \\
\hline$\# 8$ & "Discrete choice" \\
\hline \#9 & "Decision analysis" \\
\hline$\# 10$ & "Preference" \\
\hline \#II & "Multi-criteria decision analysis" \\
\hline$\# 12$ & "Multi-attribute utility" \\
\hline$\# 13$ & "Analytic hierarchy process" \\
\hline$\# 14$ & “Trade-off” \\
\hline$\# 15$ & "Risk-benefit trade-off" \\
\hline$\# 16$ & "Preference weight" \\
\hline$\# 17$ & "Willingness to pay" \\
\hline$\# 18$ & “WTP” \\
\hline$\# 19$ & "Willingness to accept" \\
\hline \multirow[t]{3}{*}{ Research search } & \#3 AND \#4 OR \#5 OR \#6 OR \#7 OR \#8 OR \#9 OR \# I \\
\hline & OR \#I I OR \#I 2 OR \#I 2 OR \#13 OR \#I 4 OR \#I 5 OR \\
\hline & \#16 OR \#17 OR \#18 OR \#19 \\
\hline
\end{tabular}

Abbreviations: DCE, discrete choice experiments; MS, multiple sclerosis; WTP, willingness to pay.

\section{Publish your work in this journal}

Patient Preference and Adherence is an international, peer-reviewed, open access journal that focuses on the growing importance of patient preference and adherence throughout the therapeutic continuum. Patient satisfaction, acceptability, quality of life, compliance, persistence and their role in developing new therapeutic modalities and compounds to optimize clinical outcomes for existing disease states are major areas of interest for the journal. This journal has been accepted for indexing on PubMed Central. The manuscript management system is completely online and includes a very quick and fair peer-review system, which is all easy to use. Visit http://www. dovepress.com/testimonials.php to read real quotes from published authors.

Submit your manuscript here: http://www.dovepress.com/patient-preference-and-adherence-journal 